\title{
Female Somalian patient with heart failure diagnosed with tropical endomycocardial fibrosis: A Case Report
}

\author{
Alev Kalkan ${ }^{1 *}$, Darius Dabir ${ }^{2}$, Karin Klingel ${ }^{3}$, Georg Nickenig ${ }^{1}$, Nikos Werner ${ }^{1}$ and Ulrich M Becher ${ }^{1}$ \\ ${ }^{1}$ Department of Cardiology, University hospital of Bonn, Bonn, Germany \\ ${ }^{2}$ Department of Radiology, University hospital of Bonn, Bonn, Germany \\ ${ }^{3}$ Department of Pathology, University hospital of Tübingen, Tübingen, Germany
}

\begin{abstract}
Introduction: Tropical endomyocardial fibrosis (TEMF) is a rare disease in western countries with higher-prevalence in tropical low-income countries. On clinical presentation affected patients suffer from symptoms of heart failure. One major characteristic feature is a cardiac diastolic dysfunction caused by the deposition of fibrous tissue within the endomyocardium. Thereby, TEMF is a seldom differential diagnosis of restrictive cardiomyopathy in patients with signs and symptoms of heart failure.

Case Representation: Here, we report about a Somalian female patient presenting at the emergency department with progressive breathlessness (NYHA IV) finally diagnosed with TEMF due to characteristic features in echocardiography, cardiac MR-imaging and histopathology findings of the myocardial biopsy

Discussion: TEMF is a rarely diagnosed disease with an insufficient elucidated etiology. In patients with restrictive heart disease suffering of signs and symptoms due to heart failure, thorough workup is pivotal to identify even seldom cases of possible primary cause. An early medical treatment should be started to reduce morbidity and mortality.
\end{abstract}

\section{Introduction}

Endomyocardial fibrosis is a heart disease which primarily affects children and young adults in tropical countries, especially in SubSaharan Africa, South America and Asia. The first case is described by Davies in 1948 in Uganda [1]. In the seventies, EMF was the fourth most common reason of myocardial disease in Africa. Today, it is considered as a rare disease [2].

Pathophysiologically, it is characterized by a deposition of fibrous tissue in the endomyocardium [3]. Fibrosis causes an increased myocardial stiffness and a diastolic dysfunction leading to a heart failure in the long term [2]. If the papillary muscles are involved, the patient of ten develops an insufficiency of the mitral and tricuspid valve [4]. However, EMF combined with a severe aortic valve stenosis is less common [1].

Although the cause for the development of TEMF is incompletely elucidated, a multifactorial pathophysiology is assumed. Among others, poverty, nutrition, genetic factors and the history of parasitic disease including Schistosoma, Filariasis and Malaria are possible risk factors [3].

In the early stages of the disease, an active phase with inflammation is predominantly described for which an eosinophil-mast cell-fibroblast cross-talk seem to be a key factor. In the chronic phase, biventricular involvement is characteristic feature of this cardiomyopathy [3,5]. An association between HLA alleles and cases of EMF is described in Mozambique and Uganda [6]. Furthermore, an EMF is considered as a late burn-out phase of Loeffler's endocarditis which is characterized by an eosinophilic myocarditis [7].

Because of the unknown etiology, the therapy is based on a symptomatic treatment of heart failure. In the early phases of the disease a surgical therapy with endocardectomy and valve repair could increase the survival [3].

\section{Case report}

A 44 years old female patient from Somalia who has lived 20 years in the Netherlands, was hospitalized because of cholecystitis treated conservatively with intravenous antibiotic. Aspects in her medical history were a known heart failure syndrome and atrial fibrillation. In May 2018, the ejection fraction was measured 30\% and an anticongestive therapy was started. The etiology of heart failure was not determined before. The patient complained about weakness and a progressive dyspnoea finally at rest (NYHA IV).

The patient had a Body Mass Index (BMI) of $20,3 \mathrm{~kg} / \mathrm{m}^{2}$. On clinical examination, bilateral basal crepitations of the lung were noticed. In the electocardiogramm, a normofrequent atrial fibrillation was recorded. The chest X-ray showed a cardiomegaly (Figure 1). The patient had normal kidney function and haemoglobin. The initial NTproBNP measured $2737 \mathrm{pg} / \mathrm{ml}$ (normal $<125 \mathrm{pg} / \mathrm{ml}$ ). The transthoracic two-dimensional echocardiography revealed a highly reduced pump function with an ejection fraction of $18 \%$ and a mitral- and tricuspidal regurgitation grade III (Figure 2).

${ }^{\star}$ Correspondence to: Alev Kalkan, Department of Internal Medicine II, Sigmund-Freud-Str. 25 University Hospital Bonn, 53105 Bonn, Germany, Tel: +49-228-287-12330/-12339; E-mail: alev.kalkan@ukbonn.de

Key words: tropical endomyocardial fibrosis, TEMF, endomyocardial fibrosis, loffler endocarditis, heart failure

Received: April 14, 2019; Accepted: April 24, 2019; Published: April 29, 2019 


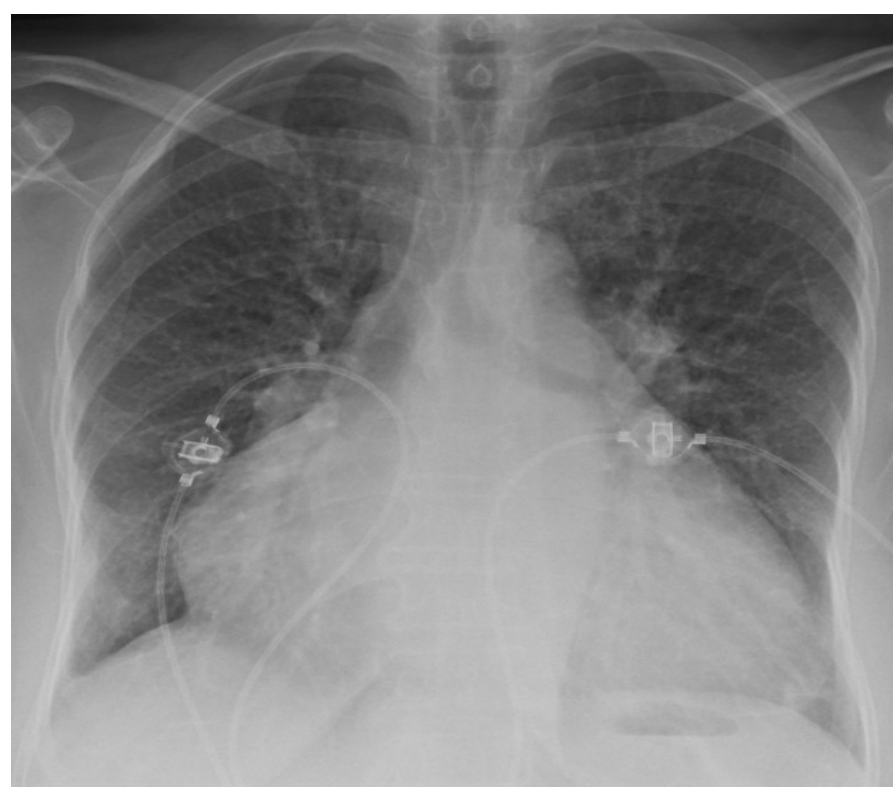

Figure 1. Chest X-ray with a severe cardiomegaly caused by biatrial dilatation

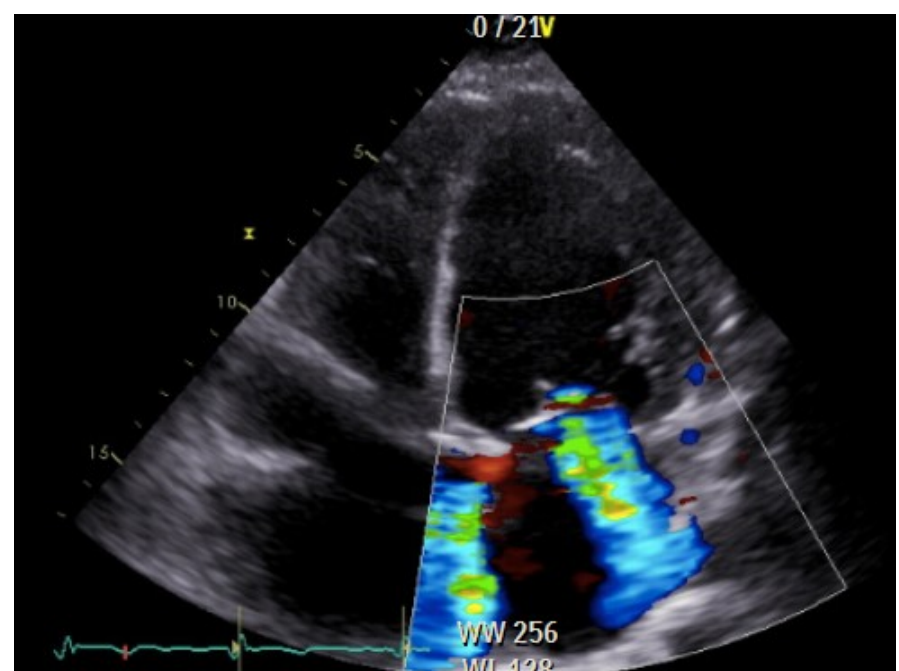

Figure 2. Transthoracic echocardiography: Apical four chamber view showing a functional mitral regurgitation (fMR) grade III

Electrical cardioversion was not successful. The coronary angiography excluded any form of coronary vessel disease (Figure 3). For further investigation, a cardiac Magnetic Resonance Imaging was performed and showed a late gadolinium enhancement with circumferential subendomyocardial enhancement (Figure 4) with like a Loffler-Endocarditis. Therefore, a treatment with oral corticosteroids was started. Furthermore, a myocardbiopsy was accomplished. The Massom Trichom Stain and the SM-Actin Immunhistology showed the pathology of an endomyocardial fibrosis without typical signs of a Loffler-Endocarditis (Figure 5). The corticosteroid therapy was stopped, and heart failure medication was intensified via Sacubitril/ Valsartan $\left(\right.$ Entresto $\left.^{\circ}\right)$. Because of the highly reduced ejection fraction, irreversible fibrotic stage and the risk of sudden cardiac death caused by ventricular arrhythmia, a cardiac defibrillator was implanted. After recompensation the transthoracic echocardiography showed an improvement of the mitral and tricuspidal regurgitation and a slowly decreasing NT-proBNP of 2375ng/l.

\section{Discussion}

Here, we report about a case of a 44 years old female patient originally from Somalia. She had no family history of cardiomyopathies, however, was hospitalized in our emergency department due to worsening of dyspnoea, on presentation stage NYHA IV. After the diagnostic workup, we diagnosed biventricular Tropical Endomyocardial fibrosis (TEMF), a rare disease in the western world with higher prevalence in Africa, South America and Asia (India). For unknown reasons, the
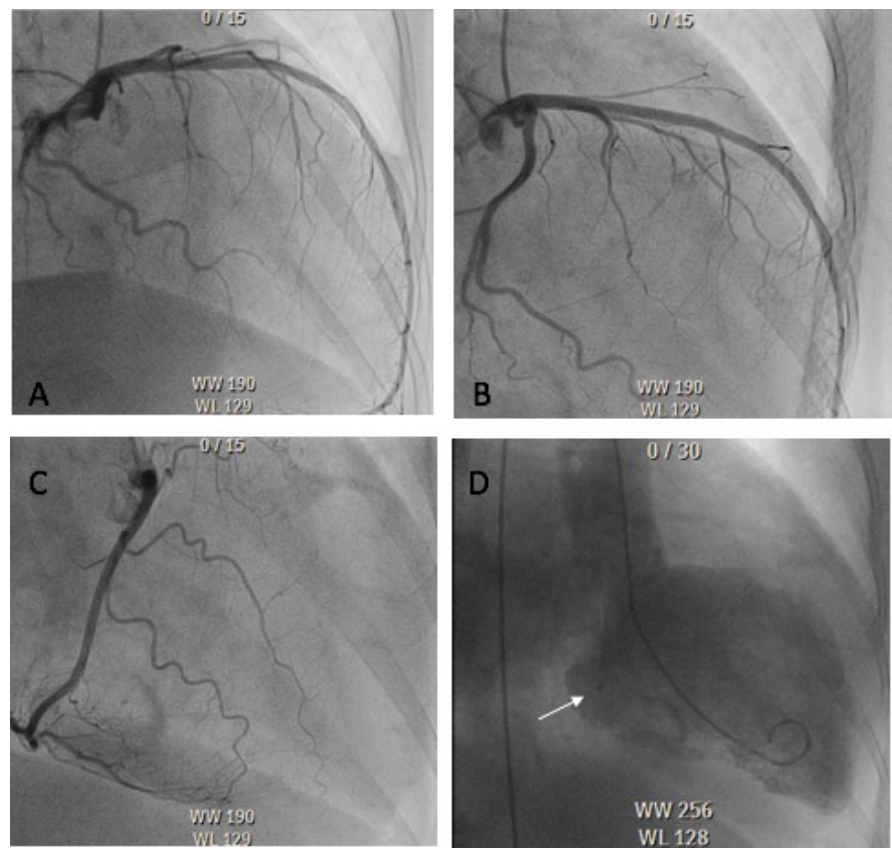

Figure 3. Coronary angiography: Left coronary artery $(A+B)$ and the right coronary artery (C). Leavo-cardiography (D) with mitral-regurgitation (arrow)
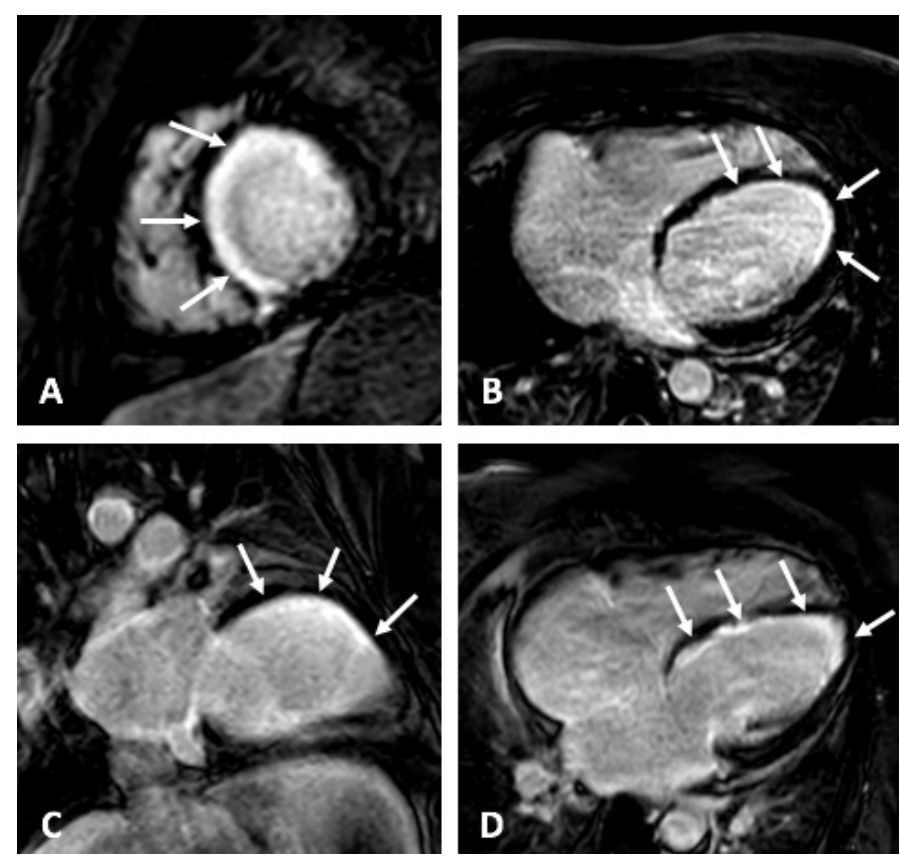

Figure 4. Late gadolinium enhancement imaging (LGE) in short axis (A), transversal (B), vertical long axis (C), and horizontal long axis (D) view with circumferential subendo myocardial enhancement (white band along the endocard, arrows). 


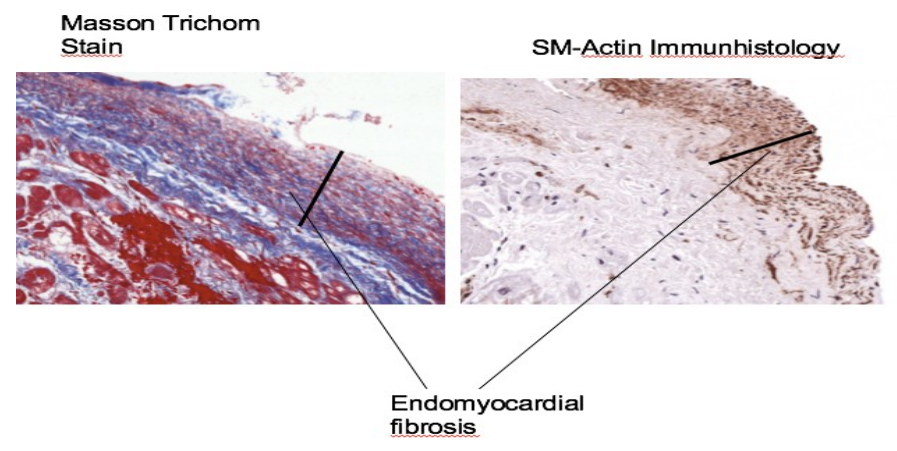

Figure 5. Myocardbiopsy showing endomyocardial fibrosis in Massom Trichom Stain and SM- Actin Immunhistology $(200 \times$ magnification $)$

disease has become less common even in Africa when compared to the 1970s. Especially in Europa, TEMF is extremely rare. However, due to the fact of worldwide tourism and refugees, TEMF is now more likely to be present in European hospitals.

In order to establish a causal treatment for TEMF, it is necessary to elucidate the pathophysiology of the disease and launch multicentric epidemiological based studies. With the help of case control studies, possible risk factors might be identified in the future.

The actual prevalence of EMF in Africa is only roughly estimated because patients from remote rural areas are not included, therefore presumably underestimating the disease burden. It seems important to note, that an early diagnosis of TEMF could significantly improve the clinical outcome of the patients. Particularly about the fact, that most patient diagnosed with TEMF are young.

\section{Conclusion}

In patients with progressive dyspnoea and signs of restrictive and systolic heart failure, thorough workups are needed to identify any possible primary cause, even the very rare etiology of TEMF. An early medical treatment should be started to reduce morbidity and mortality. One important future topic is to clarify the etiology of this disease.

\section{References}

1. Soman SO, Vijayaraghavan G, Pillai R, Muneer AR, Teena MV (2017) Biventricular Endomyocardial Fibrosis with Severe Aortic Stenosis. JIndian Acad Echocardiographic Cardiovasc Imaging 1: 60-62.

2. Falase A, Okechukwu O (2012) Cardiomyopathies and myocardial disorders in Africa: present status and the wax forward. Cardiovasc J Afr 23: 552-562. [Crossref]

3. Grimaldi A, Mocumbi AO, Freers J, Lachaud M, Mirabel M, etc. (2016) Tropical Endomyocardial Fibrosis. Circulation 133: 2503- 2515. [Crossref]

4. Hassan WM, Fawzy ME, Al Helaly S, Hegazy H, Malik S (2005) Pitfalls in Diagnosis and Clinical, Echocardiographic, and Hemodynamic Findings in Endomyocardial Fibrosis. Chest 128: 2985-3992. [Crossref]

5. Sliwa K, Damasceno A, Mayosi BM (2005) Epidemiology and Etiology of Cardiomyopathi in Africa. Circulation 112: 3577-3583.

6. Beaton A, Sable C, Brown J, Hofmann J, Mungoma M (2014) Genetic susceptibility to endomyocardial fibrosis. Glob Cardiol Sci Pract 2014: 473-481. [Crossref]

7. Sandhu HS, Mahendrakar SM, Pethani RR, Khan AH, Loya YS (2016) Severe Left Ventricular Endomyocardial Fibrosis Presenting as Biventricular Failure in a Yound Adult: A Case Report. J Clin Diagn Res 10: OD05-OD06. [Crossref]

Copyright: $\odot 2019$ Kalkan A. This is an open-access article distributed under the terms of the Creative Commons Attribution License, which permits unrestricted use, distribution, and reproduction in any medium, provided the original author and source are credited. 